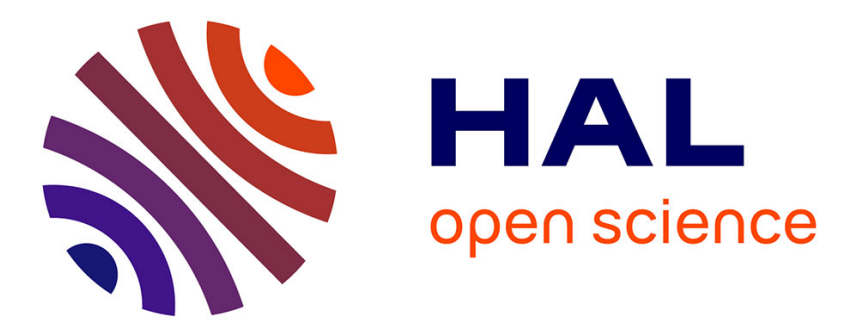

\title{
Synthesis, electrochemical and spectroscopic investigations of news N-BEDOT derivatives containing anil substituted carbazole subunits.
}

I. Fabre-Francke, M. Zagorska, G. Louarn, P. Hapiot, A. Pron, S. Sadki

\section{- To cite this version:}

I. Fabre-Francke, M. Zagorska, G. Louarn, P. Hapiot, A. Pron, et al.. Synthesis, electrochemical and spectroscopic investigations of news N-BEDOT derivatives containing anil substituted carbazole subunits.. Electrochimica Acta, 2008, 53, pp.6469-6476. 10.1016/j.electacta.2008.04.049 . hal-00344664

\author{
HAL Id: hal-00344664 \\ https://hal.science/hal-00344664
}

Submitted on 30 Mar 2009

HAL is a multi-disciplinary open access archive for the deposit and dissemination of scientific research documents, whether they are published or not. The documents may come from teaching and research institutions in France or abroad, or from public or private research centers.
L'archive ouverte pluridisciplinaire HAL, est destinée au dépôt et à la diffusion de documents scientifiques de niveau recherche, publiés ou non, émanant des établissements d'enseignement et de recherche français ou étrangers, des laboratoires publics ou privés. 


\title{
Synthesis, electrochemical and spectroscopic investigations
}

\section{of New N-BEDOT derivatives containing anil substituted carbazole}

\section{subunits}

Isabelle Fabre-Francke ${ }^{\mathrm{a}, \mathrm{b}}$, Malgorzata Zagorska ${ }^{\mathrm{c}}$, Guy Louarn ${ }^{\mathrm{d}}$, Philippe Hapiot ${ }^{\mathrm{e}}$ Adam Pron ${ }^{\mathrm{b} *}$, Saïd Sadki ${ }^{\mathrm{b}, *}$

${ }^{a}$ CEA-LETI-MINATEC

${ }^{b}$ DRFMC Structures et Propriétés d'Architectures Moléculaires, UMR-5819

Laboratoire d'Electronique Moléculaire Organique et Hybride,

17 rue des Martyrs, 38054 Grenoble cedex 9, France

${ }^{c}$ Faculty of Chemistry, Warsaw University of technology, Noakowskiego 3, 00 664, Warszawa, Poland

${ }^{d}$ Institut des Matériaux Jean Rouxel (IMN), Université de Nantes-CNRS, France

${ }^{e}$ Sciences Chimiques de Rennes, UMR CNRS 6226 - Université de Rennes 1. Equipe Matière Condensée et Systèmes Electroactifs. Campus de Beaulieu 35042 Rennes Cedex France

\footnotetext{
* Corresponding author. Tel.: +33-438-783-536; fax: +33-438-785-691

E-mail address: said.sadki@cea.fr (S. Sadki) and adam.pron@cea.fr (A. Pron)
}

\begin{abstract}
A conjugated oligomer containing central bi-ethylenedioxythiophene (BEDOT) unit and two terminal anil-substituted carbazole units has been successfully synthesized and characterized by cyclic voltammetry and spectroelectrochemical methods (UV-vis-NIR and Raman). It shows two oxidation waves at $-0.01 \mathrm{~V}$ and $+0.24 \mathrm{~V}$ ( $v s \mathrm{Fc} / \mathrm{Fc}+$ ), which can be ascribed to two
\end{abstract}


successive oxidative doping of the molecule. The molecule is transmissive sharp yellow when fully reduced, transmissive green upon oxidation up to the end of the first oxidative process, and dark blue upon full oxidation. UV-vis-NIR and Raman spectroelectrochemical investigations show that the color changes within the potential of the first oxidation wave are associated with the oxidation of both carbazole and ethylenedioxythiophene subunits whereas the electrochromic effect in the potential range of the second oxidation wave involves predominantly the oxidation of the ethylenedioxythiophene subuntits.

Keywords: Electrodimerization, spectroelectrochemistry, Raman spectroscopy, Anils, Cyclic voltamperometry, $\pi$-Conjugated oligomers

\section{Introduction}

The past 25 years have witnessed the emergence of conjugated oligomers and polymers as an important class of electroactive and photoactive materials investigated in academic as well as in industrial laboratories [1]. $\pi$-conjugated small molecules and short oligomers have attracted much attention not only in the area of organic chemistry as challenging synthetic objects but also in materials chemistry and materials science because of their promising electronic, opto-electronic and electrochemical properties [2-3]. $\pi$-conjugated oligomers can be used as model compounds for conducting polymers since their monodispersity, defectless structure and better supramolecular organization in the solid state facilitate their experimental and theoretical investigations [4]. More recently they have attracted interest as the sole active components of organic electronic or electrochemical devices $[5,6]$. The advantage of the oligomer approach relies on the possibility of their physical properties tuning by changing their chemical structure e.g. by introduction of solubilising chains, end- 
capping groups, insertion of certain specific functional groups, and by varying the oligomer length.

Among other $\pi$-conjugated systems those containing carbazole subunits deserve a special attention. Due to its unique properties, carbazole has been widely used as a functional substituent or a building block in non-linear optic (NLO) materials [7], hole transport and light-emissive materials for OLED devices [8] and as a host material for photoluminescence applications [9]. Moreover thermal stability and glassy state durability of organic molecules were found to be significantly improved upon incorporation of a carbazole moiety in their structure.

In this paper, we describe the successful synthesis and the electrodimerization of bromo EDOT-Carbazole functionalized by anils group. Our interest in this molecule is twofold. First, it is electrochemically active, showing interesting electrochromic and spectroelectrochemical behaviour. Second, it belongs to the so-called "push-pull" molecules [10]. These original compounds are composed of three parts: a donor group that is the polymerizable moiety, a $\pi$-conjugated transmettor group and an acceptor group, the photochromic unit. Such fully conjugated molecules are especially interesting because of the possibility for a cooperative interaction between the polymer part and the photochrome due to the continuous electronic conjugation. Some Schiff bases like anils (also called salicylidenesanilines) are known to undergo a photochemically induced reversible tautomeric reaction between the enol and the keto states [11]. In solution, due to its short lifetime, keto form cannot be observed except by transient spectroscopy techniques. However, in the solid state, a (near-) UV irradiation changes the yellow solid to a red one. Fundamental theoretical and spectroscopic studies have been conducted to elucidate this mechanism [12], and anils were also described as promising switching materials [13] as well as precursors to design various new metal complexes and as suitable models for pyridoxal and $\mathrm{B}_{6}$ vitamins [14]. The 
photochromism of anil substituted carbazole-ethylenedioxythiophene oligomer will be subject of a separate publication. Here we concentrate on the synthesis of this compound, its voltammetric and spectroelectrochemical (UV-vis-NIR, Raman) characterization in view to demonstrate its interesting electrochemical and electrochromic behaviour.

\section{Experimental}

General Procedure. Tetrabutylammonium perchlorate (Fluka), synthesis grade ethyl alcohol anhydrous (Carlo Erba, RS), $\mathrm{CH}_{2} \mathrm{Cl}_{2}$ (SDS, purex), hexane (Aldrich), N,N-diméthylformamide (DMF) (Carlo Erba, RPE), $\mathrm{Et}_{2} \mathrm{O}$ (Carlo Erba, RPE) and pyridine (SDS) were used as received.

Acetonitrile (Aldrich, HPLC gradient grade) was distilled under $\mathrm{N}_{2}$ immediately before use from $\mathrm{P}_{2} \mathrm{O}_{5}$. Tetrahydrofuran (THF) was purified by distillation from sodium/benzophenone under $\mathrm{N}_{2}$ immediately before use.

Moisture and oxygen sensitive reactions were carried out in flame-dried glassware under Ar. Column chromatography was carried out under positive pressure using $0.063-0.2$ nm silica gel (Merck) and the indicated solvents. Evaporations were conducted under reduced pressure at temperatures lower than $45^{\circ} \mathrm{C}$, unless otherwise noted. Further drying of the residue was accomplished under high vacuum. FTIR analyses were carried out on a PerkinElmer IR-FT 1600 spectrometer whereas the NMR spectra in the indicated solvent were run on a $200 \mathrm{MHz}$ Bruker spectrometer. Liquid secondary ion mass spectrometry low-resolution data (LSIMS) were obtained from the mass spectrometry laboratory of the CERMAV at the University of Grenoble, Grenoble, France. Liquid secondary ion mass spectrometry hightresolution data (HMRS) were obtained from the mass spectrometry laboratory of the CRMPO at the University of Rennes, Rennes, France. 
3,6-Dibromocarbazole (2) : To a cold $\left(0^{\circ} \mathrm{C}\right)$ solution of carbazole $(2.01 \mathrm{~g}, 12.0 \mathrm{mmol})$ in $\mathrm{CH}_{2} \mathrm{Cl}_{2}(350 \mathrm{~mL})$, first $40.50 \mathrm{~g}$ of $\mathrm{SiO}_{2}(0.063-0.2 \mathrm{~nm})\left(\right.$ dried beforehand at $\left.120^{\circ} \mathrm{C}\right)$ and then NBS (4.20 g, $23.8 \mathrm{mmol}$ ) were added under argon. After the addition, the cooling ice bath was removed and the resulting mixture was stirred overnight in dark at room temperature. The reaction mixture was then filtered and the silica washed with $\mathrm{CH}_{2} \mathrm{Cl}_{2}(3 \times 30 \mathrm{~mL})$. The combined layers were washed with brine $(3 \times 30 \mathrm{~mL})$, dried over $\mathrm{Na}_{2} \mathrm{SO}_{4}$, filtered and evaporated to give crude 2 as a white amorphous solid (2.94 g, $76 \%$ yield): IR ( $\mathrm{NaCl}) 3446$, 3047, 2981, 1262, $739 \mathrm{~cm}^{-1} ;{ }^{1} \mathrm{H}$ NMR (Acetone $\left.\mathrm{D}_{6}, 200 \mathrm{MHz}\right) \delta 7.50(\mathrm{dd}, J=0.8,8.6 \mathrm{~Hz}$, 2H), $7.55(\mathrm{dd}, J=1.7,8.6 \mathrm{~Hz}, 2 \mathrm{H}), 8.37(\mathrm{dd}, J=0.8,1.7 \mathrm{~Hz}, 2 \mathrm{H}), 10.66(\mathrm{bs}, 1 \mathrm{H}) ;{ }^{13} \mathrm{C} \mathrm{NMR}$ (Acetone $\left.\mathrm{D}_{6}, 50.3 \mathrm{MHz}\right) \delta 140.9,131.1,125.7,125.0,114.8,113.4$; LSIMS m/z (rel intensity) $326\left(\left[\mathrm{M}-\mathrm{H}^{+}\right], 53\right), 324\left(\left[\mathrm{M}-\mathrm{H}^{+}\right], 100\right), 322\left(\left[\mathrm{M}-\mathrm{H}^{+}\right], 60\right)$.

3,6-Dibromo-9-(4-nitrophenyl)-carbazole (3) : To a stirred solution of 3,6dibromocarbazole $(5.88 \mathrm{~g}, 18.1 \mathrm{mmol})$ in $\mathrm{DMF}(95 \mathrm{~mL}) 1.31 \mathrm{~g}$ of $\mathrm{NaH}(54.5 \mathrm{mmol})$ were added. The mixture was stirred during $10 \mathrm{~min}$ and in the next step 1-fluoro-4-nitrobenzene (3.34 g, $23.7 \mathrm{mmol}$ ) was added. The mixture was then stirred overnight at room temperature. After cooling to $\mathrm{ca} .0^{\circ} \mathrm{C}$, the residue was washed with $\mathrm{CH}_{2} \mathrm{Cl}_{2}$ then with hexane, filtered and evaporated to give $3(12.16 \mathrm{~g}, 100 \%$ yield) as a yellow powder. IR ( $\mathrm{NaCl}) 3050,2986,1709$, 1422, $1262 \mathrm{~cm}^{-1} ;{ }^{1} \mathrm{H} \mathrm{NMR}\left(\mathrm{CDCl}_{3}, 200 \mathrm{MHz}\right) \delta 7 . \mathrm{x} 33(\mathrm{~d}, \mathrm{~J}=8.7 \mathrm{~Hz}, 2 \mathrm{H}) ; 7.56(\mathrm{dd}, J=1.9$, $8.7 \mathrm{~Hz}, 2 \mathrm{H}) ; 7.74(\mathrm{~d}, J=8.7 \mathrm{~Hz}, 2 \mathrm{H}) ; 8.21(\mathrm{~d}, J=1.9 \mathrm{~Hz}, 2 \mathrm{H}) ; 8.50(\mathrm{~d}, J=8.7 \mathrm{~Hz}, 2 \mathrm{H})$; ${ }^{13} \mathrm{C} \mathrm{NMR}\left(\mathrm{CDCl}_{3}, 50.3 \mathrm{MHz}\right) \delta 146.3,142.7,138.9,129.9,126.8,125.9,124.7,123.6,114.3$, 111.2 ; LSIMS m/z (rel intensity) $402\left(\left[{\mathrm{M}-\mathrm{NO}_{2}}^{+}\right], 21,400\left(\left[\mathrm{M}-\mathrm{NO}_{2}{ }^{+}\right], 35\right), 398\left(\left[{\mathrm{M}-\mathrm{NO}_{2}}^{+}\right]\right.\right.$, 19), 312 (100), 319 (99).

4-(3,6-Dibromo-9-carbazol-9-yl)benzenamine (4) : To a stirred solution of sodium disulfide nonahydrate $(2.18 \mathrm{~g}, 9.0 \mathrm{mmol})$ in $5 \mathrm{~mL}$ of distilled water $307.50 \mathrm{mg}(9.6 \mathrm{mmol})$ of sulphur were added. The mixture was heated with stirring until it became homogeneous to a 
naked eye. In a flask equipped with an overhead stirrer, an addition funnel and a watercooled condenser, 3,6-Dibromo-9-(4-nitrophenyl)-carbazole (1.19 g, $2.7 \mathrm{mmol})$ in $10 \mathrm{~mL}$ of pyridine was heated to reflux. The above aqueous solution was then added over a period of 30 min to the refluxing pyridine solution, and heating was continued for an additional $6 \mathrm{~h}$. The solution was concentrated, then poured into $15 \mathrm{~mL}$ of distilled water and finally stirred overnight. The residue was washed with distilled water, filtered and evaporated to give 4 (1.10 g, 98\% yield) as a pale powder. IR (NaCl) 3402, 3018, $1215 \mathrm{~cm}^{-1} ;{ }^{1} \mathrm{H}$ NMR (acetone, $200 \mathrm{MHz}) \delta 8.43(\mathrm{~d}, J=1.9 \mathrm{~Hz}, 2 \mathrm{H}) ; 7.56(\mathrm{dd}, J=1.9,8.7 \mathrm{~Hz}, 2 \mathrm{H}) ; 7.23(\mathrm{dd}, J=4.1,8.7$ $\mathrm{Hz}, 4 \mathrm{H}) ; 6.93(\mathrm{~d}, J=8.5 \mathrm{~Hz}, 2 \mathrm{H}) ; 5.08(\mathrm{bs}, 2 \mathrm{H}) ;{ }^{13} \mathrm{C}$ NMR (acetone, $\left.50.3 \mathrm{MHz}\right) \delta 150.8$, $142.5,131.0,129.8,126.6,125.3,125.1,116.9,113.9,113.7$; LSIMS m/z (rel intensity) 419 ([M-H $\left.\left.{ }^{+}\right], 52\right), 417\left(\left[\mathrm{M}-\mathrm{H}^{+}\right], 100\right), 415\left(\left[\mathrm{M}-\mathrm{H}^{+}\right], 58\right), 339(65), 337$ (52).

2,4-Di-tert-butyl-6-((4-(3,6-dibromocarbazole-9-yl)-phenylimino)-methyl)-phenol (5) : To 4-(3,6-Dibromo-9-carbazol-9-yl)benzenamine $(467.40 \mathrm{mg}, 1.1 \mathrm{mmol})$ in $30 \mathrm{~mL}$ of ethanol $290.10 \mathrm{mg}$, (1.2 mmol) of 3,5-di-tert-butyl-2-hydroxy-benzaldehyde were added and the resulting solution was heated to reflux for $2 \mathrm{~d}$. Then it was cooled to room temperature and the precipitate was collected by filtration, washed with ethanol and dried under vaccum to give 5 (734.40 mg, 79\% yield) as a yellow solid. IR (NaCl) 3372, 2959, $1513 \mathrm{~cm}^{-1} ;{ }^{1} \mathrm{H} \mathrm{NMR}$ $\left(\mathrm{CDCl}_{3}, 200 \mathrm{MHz}\right) \delta 1.36(\mathrm{~s}, 9 \mathrm{H}), 1.50(\mathrm{~s}, 9 \mathrm{H}), 7.28(\mathrm{dd}, J=2.8,5.3 \mathrm{~Hz}, 2 \mathrm{H}), 7.52(\mathrm{~m}, 8 \mathrm{H})$,

$8.21(\mathrm{~d}, \mathrm{~J}=1.7 \mathrm{~Hz}, 2 \mathrm{H}), 8.75(\mathrm{~s}, 1 \mathrm{H}), 13.51(\mathrm{~s}, 1 \mathrm{H}) ;{ }^{13} \mathrm{C} \mathrm{NMR}\left(\mathrm{CDCl}_{3}, 50.3 \mathrm{MHz}\right) \delta 164.7$, $158.3,148.4,140.9,139.9,137.2,134.9,129.4,128.6,127.9,127.0,123.9,123.2,122.8$, 118.2, 113.2, 111.5, 35.1, 34.2, 31.5, 29.4 ; LSIMS m/z (rel intensity) 635 ([M-H $\left.\left.{ }^{+}\right], 53\right), 633$ $\left(\left[\mathrm{M}-\mathrm{H}^{+}\right], 100\right), 631\left(\left[\mathrm{M}-\mathrm{H}^{+}\right], 43\right), 619$ (3), 617 (5), 615 (3) ; HMRS (LSIMS) calcd for $\mathrm{C}_{33} \mathrm{H}_{33} \mathrm{~N}_{2} \mathrm{OBr}_{2} 631.0960$ Found 631.0958.

3,5-Di-tert-butyl-2-(trimethylsilyloxy)benzylidene)-4-(3,6-dibromocarbazole-9yl)benzenamine (6) : To a stirred ice-cold suspension of 2,4-Di-tert-butyl-6-((4-(3,6- 
dibromocarbazole-9-yl)-phenylimino)-methyl)-phenol (1.00 g, $1.6 \mathrm{mmol})$ in dry $\mathrm{CH}_{2} \mathrm{Cl}_{2}(25$ $\mathrm{mL}) 1.30 \mathrm{~mL}(9.3 \mathrm{mmol})$ of triethylamine and $1.11 \mathrm{~g}(9.1 \mathrm{mmol})$ of 4-dimethymaminopyridine were added. The mixture was stirred for $10 \mathrm{~min}$, then trimethylsilyl chloride (TMSCl, $1.4 \mathrm{~mL}$, $11.0 \mathrm{mmol}$ ) was added. After $30 \mathrm{~min}$, the cooling ice bath was removed and the mixture was stirred overnight at room temperature. The solution was diluted in $20 \mathrm{~mL} \mathrm{of} \mathrm{CH}_{2} \mathrm{Cl}_{2}$, washed with $1 \mathrm{M} \mathrm{H}_{3} \mathrm{PO}_{4}(4 \times 10 \mathrm{~mL})$ and brine $(4 \times 10 \mathrm{~mL})$. The organic layer was dried over $\mathrm{Na}_{2} \mathrm{SO}_{4}$, filtered and evaporated to give crude 6 as a yellow solid, (1.06 g, 94\% yield). ${ }^{1} \mathrm{H}$ NMR $\left(\mathrm{CDCl}_{3}, 200 \mathrm{MHz}\right) \delta 0.32(\mathrm{~s}, 9 \mathrm{H}), 1.35(\mathrm{~s}, 9 \mathrm{H}), 1.54(\mathrm{~s}, 9 \mathrm{H}), 7.55-7.24(\mathrm{~m}, 10 \mathrm{H}), 8.18(\mathrm{~d}, \mathrm{~J}=$ $1.9 \mathrm{~Hz}, 2 \mathrm{H}), 8.76(\mathrm{~s}, 1 \mathrm{H}) ;{ }^{13} \mathrm{C} \mathrm{NMR}\left(\mathrm{CDCl}_{3}, 50.3 \mathrm{MHz}\right) \delta 164.7,159.1,158.4,148.5,140.9$, $139.9,137.3,134.9,131.8,129.5,128.6,127.9,127.0,124.0,123.2,122.8,120.1,118.3$, 113.2, 111.4, 35.2, 34.2, 31.5, 29.5, 14.6 ; LSIMS m/z (rel intensity) 635 ([M-SiCH$\left.\left.{ }^{+}\right], 34\right)$, 634 (53), $633\left(\left[{\mathrm{M}-\mathrm{SiCH}_{3}}^{+}\right], 100\right), 632$ (93), $631\left(\left[{\mathrm{M}-\mathrm{SiCH}_{3}}^{+}\right], 67\right), 630$ (49).

(2,3-dihydrothieno[3,4][1,4]dioxin-5-yl)trimethylstannane (7) : To a solution of 3,4ethylenedioxythiophene $(1.13 \mathrm{~g}, 8.0 \mathrm{mmol})$ in THF $(10 \mathrm{~mL}) n$-butyllithium $(6.1 \mathrm{~mL}, 11.9 \mathrm{mmol}$, 2.5 $\mathrm{M}$ in hexanes) was added dropwise at $-78^{\circ} \mathrm{C}$. The mixture was stirred at room temperature for $1 \mathrm{~h}$ and cooled at $-78^{\circ} \mathrm{C}$. Trimethyltin chloride $(1.67 \mathrm{~g}, 8.4 \mathrm{mmol})$ in THF (5 $\mathrm{mL}$ ) was added dropwise, and the resulting mixture was stirred at $-78^{\circ} \mathrm{C}$ for $4 \mathrm{~h}$ and then allowed to warm to room temperature overnight. The solution was diluted in $30 \mathrm{~mL}$ of $\mathrm{Et}_{2} \mathrm{O}$, washed with saturated solution of $\mathrm{NH}_{4} \mathrm{Cl}(6 \times 20 \mathrm{~mL})$. The organic layer was dried over $\mathrm{Na}_{2} \mathrm{SO}_{4}$, filtered and evaporated to give crude as a brown oil, which contains $1.61 \mathrm{~g}(67 \%$ yield) of 7 , along with $0.37 \mathrm{~g}$ of the starting material as determined by ${ }^{1} \mathrm{H}$ NMR. Compound 7 was used in the subsequent step without further purification. ${ }^{1} \mathrm{H} \mathrm{NMR}\left(\mathrm{CDCl}_{3}, 200 \mathrm{MHz}\right): \delta$ $6.61(\mathrm{~s}, 1 \mathrm{H}), 4.20(\mathrm{~m}, 4 \mathrm{H}), 0.38(\mathrm{~s}, 9 \mathrm{H})$.

Monomer EDOT-Cz-Anil 8: 3,5-di-tert-butyl-2-(trimethylsilyloxy)benzylidene)-4-(3,6dibromocarbazole-9-yl)benzenamine (986.00 mg, $1.4 \mathrm{mmol})$, compound 7 (1.61 g, $5.3 \mathrm{mmol})$ 
and $\mathrm{Pd}\left(\mathrm{PPh}_{3}\right)_{4}(142.70 \mathrm{mg}, 0.12 \mathrm{mmol})$ were added to THF $(25 \mathrm{~mL})$. The mixture was stirred at $85^{\circ} \mathrm{C}$ overnight under nitrogen. THF was then evaporated to give oil. The residue was purified by column chromatography, eluting with hexane- $\mathrm{CH}_{2} \mathrm{Cl}_{2}(4: 1 \rightarrow 1: 1)$, to afford 8 as a yellow-green solid (203.70 mg, 21\% yield). IR (NaCl) $\mathrm{cm}^{-1} 3380,3040,1620,1362 ;{ }^{1} \mathrm{H}$ NMR $\left(\mathrm{CDCl}_{3}, 200 \mathrm{MHz}\right) \delta 1.37(\mathrm{~s}, 9 \mathrm{H}), 1.53(\mathrm{~s}, 9 \mathrm{H}), 4.52(\mathrm{~m}, 4 \mathrm{H}), 6.31(\mathrm{~s}, 1 \mathrm{H}), 7.40(\mathrm{~m}, 4 \mathrm{H})$, $7.80(\mathrm{~d}, J=1.7 \mathrm{~Hz}, 1 \mathrm{H}), 8.30(\mathrm{~d}, J=1.7 \mathrm{~Hz}, 1 \mathrm{H}), 8.43(\mathrm{~d}, J=1.3 \mathrm{~Hz}, 1 \mathrm{H}), 8.76(\mathrm{~s}, 1 \mathrm{H})$, $13.59(\mathrm{~s}, 1 \mathrm{H}) ;{ }^{13} \mathrm{C} \mathrm{NMR}\left(\mathrm{CDCl}_{3}, 50.3 \mathrm{MHz}\right) \delta 164.4,158.3,147.9,142.2,140.8,139.9$, $139.8,137.3,137.1,135.2,128.8,128.4,127.7,127.0,125.8,125.4,125.1,123.7,123.2$, $122.6,122.5,118.2,117.2,112.9,111.3,110.0,96.8,64.8,64.5,35.1,34.2,31.4,29.4$; LSIMS m/z (rel intensity) $695\left(\left[\mathrm{M}-\mathrm{H}^{+}\right], 100\right), 693\left(\left[\mathrm{M}-\mathrm{H}^{+}\right], 91\right)$; HMRS (LSIMS) calcd for $\mathrm{C}_{39} \mathrm{H}_{38} \mathrm{~N}_{2} \mathrm{O}_{3} \mathrm{BrS} 639.1787$ Found 639.1793.

Cyclic voltammetry and spectroelectrochemical characterization. Cyclic voltammetry experiments were carried out in a $20 \mathrm{~mL}$ one compartment electrolytic cell containing $0.1 \mathrm{M}$ $\mathrm{NBu}_{4} \mathrm{ClO}_{4}$ /acetonitrile electrolytic solution with a platinum disc $\left(0.785 \mathrm{~mm}^{2}\right.$ surface area $)$ working electrode, a platinum wire counter electrode and an $\mathrm{Ag} / \mathrm{AgCl}$ reference electrode. The reference was calibrated after each experiment against the ferrocene/ferrocinium couple $\left(\mathrm{E}^{\circ} \mathrm{Fc} / \mathrm{Fc}^{+}=0.42 \mathrm{~V}\right.$ vs the $\mathrm{Ag} / \mathrm{AgCl}$ reference) as recommended by IUPAC [15]. UV-visible and Raman spectroelectrochemical studies were carried out in $\mathrm{Bu}_{4} \mathrm{NBF}_{4} /$ acetonitrile with $\mathrm{Ag} / 0.1 \mathrm{M} \mathrm{AgNO}_{3}$ in acetonitrile as a reference electrode. UV-vis-NIR spectra were recorded on a Cary 5000 (Varian) whereas the Raman ones were obtained on a FT Raman Bruker RFS 100 (excitation line $1064 \mathrm{~nm}$ ).

Quantum chemistry calculations. Calculations were performed using the Gaussian 03W package [16]. Figures were done with the Molekel molecular visualization program (Swiss National Supercomputing Centre). Gas phase geometries and electronic energies were calculated by full optimization without imposed symmetry of the conformations using the 
B3LYP [17] density functional with the $6-31 G^{*}$ basis set [18], starting from preliminary optimizations performed with semi-empirical AM1 methods.

\section{Results and discussion}

Monomer synthesis and characterization. Scheme 1 illustrates the synthetic route to the novel N-carbazole derivative $\mathbf{8}$. EDOT-Cz-Anil 8 can be synthesized from carbazole in a multi steps procedure depicted in Scheme 1. The first step involves regioselective introduction of bromine at the 3- and 6- positions of the carbazole unit, which can be accomplished with excellent yield by using 2 equivalents of N-bromosuccinimide in presence of silica gel [19]. The next three steps are aimed on the $\mathrm{N}$ functionalization of the carbazole unit with a conjugated chromophore group. In particular, the treatment of 3,6-dibromocarbazole with sodium hydride, and subsequently with 4-fluoronitrobenzene, yields 3,6-dibromo-9-(4nitrophenyl)-carbazole 3 [20]. 3 can be reduced by catalytic hydrogenation using sodium sulphide, sulphur and pyridine [21]. Then, 2,4-di-tert-butyl-6-((4-(3,6-dibromocarbazole-9yl)-phenylimino)-methyl)-phenol 5 is obtained with good yields $(79 \%)$ by the reaction of compound 4 with the corresponding aldehyde in refluxing ethanol [22]. The reaction is quantitative since the IR spectra of the product confirm the disappearance of the bands originating from the vibrations of the aldehyde group. The introduction of the 3,4ethyledioxythiophene (EDOT) is accomplished by a Stille-coupling reaction between 6, which is the protected form of compound 5, and the precursor i.e. $(2,3-$ dihydrothieno[3,4][1,4]dioxin-5-yl)trimethylstannane $7[23,24]$. The protection of the phenolic function of compound 5 is necessary to avoid possible secondary reactions. This protection is carried out under classical conditions using trimethylsilylchloride as a protecting group [25]. The set of the above outlined reactions leads to EDOT-Cz-Anil 8 in a form of a yellow powder with a global yield of $12 \%$. 
8 is electrochemically active showing, upon cycling in the potential range of 0.08 $0.98 \mathrm{~V}$, two irreversible anodic waves at $\mathrm{E}_{1}=0.48 \mathrm{~V}$ and $\mathrm{E}_{2}=0.82 \mathrm{~V}$ with no cathodic counterparts (see Fig. 1a). The first peak can unambiguously be attributed to the oxidative coupling of two monomers via their EDOT subunits (see Scheme 2) [26]. The second one is ascribed to the oxidation of the phenolic group. This attribution is supported by the comparison of the cyclic voltammograms of $\mathbf{8}$ and $\mathbf{9}$, the latter constituting this building block of $\mathbf{8}$, which contains the phenol function (compare Fig. 1 a and b) [27]. It should also be noted that the two registered oxidation waves are well separated. Therefore, if the oxidative dimerization is carried out at sufficiently low potentials, it should not be perturbed by other oxidation processes.

Electrodimerization. The selected vertex potential for the voltammeric dimerization of $\mathbf{8}$ is $0.95 \mathrm{~V}$. This value is high enough to assure the oxidative coupling of the EDOT subunits and sufficiently low to avoid the irreversible overoxidation effects clearly observed when the vertex potential is extended to $0.98 \mathrm{~V}$. Fig. 2 shows first 10 cycles of the voltammetric deposition process of dimer 10. The anodic wave clearly seen above $\mathrm{E}=0.33 \mathrm{~V}$ originates from the oxidative coupling of two monomer $\mathbf{8}$ molecules to give the corresponding dimer $\mathbf{1 0}$. This dimerization occurs via $\mathrm{C}_{\alpha^{-}} \mathrm{C}_{\alpha}$ coupling of the terminal EDOT subunits. This is understandable since the electrodonating properties of the dialkoxy substituent in the EDOT ring increase the electron density at the $\mathrm{C}_{\alpha}$ terminal carbon, facilitating its oxidation to a radical cation, followed by the carbone-carbone bond formation which by analogy with the known behaviour of other thiophene radical cation certainly occurs through the reaction between radical-cations [28]. This point is in agreement with the calculated spin density of the radical cation of the monomer 8, where the largest value is clearly visible on the terminated $\mathrm{C}_{\alpha}$ terminal carbon (Fig. 3). These calculations confirm that the oxidative coupling is very selective and only occurs on the $\mathrm{C}_{\alpha}$-position which is generally not the case 
with long thiophene oligomers [28]. It should also be noted that the dimerization product is stabilized by the conjugation between the EDOT subunit and the carbazole ones [29]. In addition to the oxidative dimerization peak, two new redox couples develop at lower potentials whose intensity increases with the number of cycles. Since both peaks of these redox couples (at -0.07 and $0.18 \mathrm{~V}$ ) have their cathodic analogue, they can be tentatively ascribed to the oxidative doping and dedoping of the EDOT part of $\mathbf{1 0}$ (vide infra).

The UV-vis-NIR spectrum of as prepared dimer 10, recorded for the open circuit potential $\left(E_{o c}=-0.04 V\right)$ is shown in Fig. 4. It is clear that at the open circuit potential 10 is partially doped which is manifested by rather strong absorption bands at $567 \mathrm{~nm}$ and 1026 $\mathrm{nm}$ ascribed to charged forms of the EDOT subunit [29].

Dimer Electrochemistry. A representative cyclic voltammogram of dimer 10, recorded in the absence of its monomer 8, is shown in Fig.5. The two redox processes at -10 and $240 \mathrm{mV}$, respectively, are indicative of the formation of charged states (radical cation and dication) in 10 [29]. The presence of three separate redox states (neutral and two charged ones), giving rise to two anodic waves in the cyclic voltammogram, is typical of oligomers or polymers containing the carbazole - BEDOT moieties. For both redox processes, the peak intensity changes linearly with the scan rate (Fig. 5b) in agreement with the behaviour expected for a deposited material. The electrodeposited dimer film demonstrates a good stability electrochemical cyclability, only negligible changes in the cyclic voltammetry curves are observed after 50 cycles at $50 \mathrm{mV} \cdot \mathrm{s}^{-1}$. Optmized calculation indicates that the molecule adopts a linear and twisted conformation in the neutral state. However, because calculations were made in gas phase, it is likely that in the material, the linear molecule becomes more planar than predicted by gas phase calculations performed on an isolated molecule (Fig.6).

UV-vis-NIR and Raman Spectroelectrochemistry. Spectroelectrochemical investigations of the dimer are important for two reasons. First, taking into account that several 
electrochemically active chromophores are present in the molecule of $\mathbf{1 0}$, it is expected that it can exhibit very interesting electrochromic behaviour. Second, voltammetric investigations are of phenomenological nature, their association with complementary spectroscopic measurements may, in favourable cases, give deeper inside into the mechanisms of the redox processes occurring in the electrochromic layer.

Fig.7 shows the UV-vis-NIR spectra of the dimer, registered for the increasing working electrode polarization. It should be noted that it is very difficult to record the spectrum of the neutral form of $\mathbf{1 0}$. At the open circuit potential it shows spectroscopic signs of partial oxidation (Fig.4). Even extended electrochemical reduction at $\mathrm{E}=-0.44 \mathrm{~V}$ does not result in a complete disappearance of the bands characteristic of the oxidized state (Fig.7). At this potential, the $\pi-\pi *$ transition band, peaked at $402 \mathrm{~nm}$, which is characteristic of the neutral polyconjugated systems, is inhomogeneously broadened due to the presence of different chromophores of limited conjugation in the molecule of 10 [30]. As a result their $\pi-\pi *$ bands, although strongly overlap, are distinguishable.

Bleaching of the $\pi-\pi *$ band with increasing electrode polarization with concomitant growth of new bands in the red and near infrared parts of the spectrum are the most characteristic spectroscopic features of the electrochemical doping of conjugated molecules [29]. In the case of $\mathbf{1 0}$, this bleaching is not uniform. We can clearly distinguish two components whose response to the electrode potential is different. The higher energetic component with a maximum at $386 \mathrm{~nm}$ decreases in its intensity in the potential range of the first oxidation wave of the cyclic voltammetry, then, upon further potential increase it undergoes no additional changes. The second component of this band, peaked at $415 \mathrm{~nm}$ starts to decrease in intensity at the potential of the onset of the first oxidation wave and continues to bleach throughout the potentials of both anodic peaks (compare Figs.5 and 7). In the same time the doping induced bands grow in intensity. These changes give rise to very 
characteristic electrochromic features of 10. The dimer is transmissive sharp yellow when fully reduced, transmissive green upon oxidation up to the end of the first oxidative process, and dark blue upon full oxidation.

Raman spectroelectrochemistry can provide further insight into the nature of the redox processes occurring in $\mathbf{1 0}$ upon increasing electrode polarization. It should be noted here that in any study of polyconjugated molecules or polymers by Raman spectroscopy, resonant effects have to be taken into account. Because of these effects, the intensity of the observed lines and sometimes their positions strongly depend on the energy of the excitation line used. Moreover, polyconjugated molecules or polymers in their undoped state (or neutral state) frequently exhibit more or less pronounced photoluminescence. This effect strongly perturbs the Raman studies and in some cases makes them impossible. Taking all above limitations into account, we have selected the infrared excitation line $\left(\lambda_{\mathrm{exc}}=1064 \mathrm{~nm}\right)$ because for this wavelength, the photoluminescence problems are non existent. Moreover, this excitation line enhances the bands originating from the doped (or oxidized) form of the molecule. It is therefore almost ideally suitable for the spectroelectrochemical studies.

In Fig.8 the spectra of 10, recorded for increasing electrode potentials, are collected. We will concentrate first on the on the attribution of the Raman bands recorded for the most negative potential i.e. for the reduced form of the dimer. The bands characteristic of both ethylenedioxythiophene and carbazole subunits can clearly be distinguished. In particular, the band at $1460 \mathrm{~cm}^{-1}$ can without ambiguity be attributed to the $\mathrm{C}_{\alpha}-\mathrm{C}_{\beta}$ stretching in the substituted thiophene ring. Other bands originating from the ethylenedioxythiophene vibrations are: $1246 \mathrm{~cm}^{-1}$ interring stretching, $1123 \mathrm{~cm}^{-1}\left(\mathrm{C}_{\beta}-\mathrm{O}\right), 700 \mathrm{~cm}^{-1}(\mathrm{C}-\mathrm{S}-\mathrm{C}$ thiophene deformation) [31a].

The band at $1323 \mathrm{~cm}^{-1}$ is assigned to the $\mathrm{C}-\mathrm{C}$ interring bridge stretching whereas the bands at $1483 \mathrm{~cm}^{-1}$ and $1624 \mathrm{~cm}^{-1}$ to $\mathrm{C}-\mathrm{C}$ stretchings the aromatic ring of the carbazole moiety [31b]. 
The very intensive band at $1552 \mathrm{~cm}^{-1}$ can originate from the carbazole subunit but also from the azomethine group $(\mathrm{CH}=\mathrm{N})$ [31c]. Taking into account that it is broader and more intensive than in other carbazole derivatives, we tend to believe that it embraces contributions from both the carbazole moiety and the azomethine group.

The doping induced shifts in the Raman bands originating from the vibrations of the conjugated backbone start at the potentials characteristic of the onset of the first oxidation wave. In particular the line at $1552 \mathrm{~cm}^{-1}$ shifts towards lower wavenumbers, which we attribute to the oxidation of the carbazole subunit. The oxidation process, via conjugation, also affects the azomethine group of the substituent. This shift is much more pronounced at the potentials of the first oxidation wave $\left(23 \mathrm{~cm}^{-1}\right)$ than at the potentials of the second one (8 $\mathrm{cm}^{-1}$ ) (compare Figs.5 and 8). The observed behaviour strongly suggests that the higher energetic component of the $\pi-\pi *$ band of $\mathbf{1 0}$ (Fig.7) originates from the carbazole subunit because its spectroscopic response to the potential increase is very similar to that observed for the Raman band at $1552 \mathrm{~cm}^{-1}$.

The band diagnostic of the ethylenedioxythiophene moiety, at $1460 \mathrm{~cm}^{-1}$ in the neutral form of the dimer, upon oxidation monotonically decreases in intensity with respect to the bands originating from the cabazole subunit. It also undergoes a shift of $8 \mathrm{~cm}^{-1}$ when going from $\mathrm{E}=-0.44 \mathrm{~V}$ to $\mathrm{E}=+0.46 \mathrm{~V}$. As a consequence, for the doped state, the bands originating form the carbazole subunit (especially the bands at $1485 \mathrm{~cm}^{-1}$ and at $1586 \mathrm{~cm}^{-1}$ ) become more clearly visible. It should also be noted that this oxidation occurs within the potentials of both oxidation waves. Such behaviour is typical of the oxidative doping of ethylenedioxythiophene-based oligomers and polymers [31a].

Thus, complementary spectroelecrochemical studies (UV-vis-NIR and Raman) clearly indicate that both subunits of the dimer are oxidatively doped, however in the carbazole 
subunit the doping is restricted to the potentials of the first oxidation wave whereas in the BEDOT one it is continued throughout the second oxidation wave.

\section{Conclusions}

To summarize, we have developed a new conjugated oligomer of interesting electrochromic and spectroelectrochemical properties. It can be conveniently deposited on a suitable electrode by dimerization of a monomer containing ethylene-dioxythiophene-carbazole-anil subunits (EDOT-Cz-Anil). The resulting dimer is transmissive sharp yellow when fully reduced, transmissive green upon oxidation up to the end of the first oxidative process, and dark blue upon full oxidation. As shown by complementary UV-vis-NIR and Raman spectroelectrochemical studies, the first colour change (from yellow to green) is caused by the oxidation of both carbazole and ethylenedioxythiophene subunits whereas the second one (from green to blue) by further oxidation of the ethylenedioxythiophene subunits.

\section{References}

[1] (a) Handbook of Conducting Polymers, ed. T. A. Skotheim, R.L. Elsenbaumer and J. R. Reynolds, $2^{\text {nd }}$ edn, Marcel Dekker, New York 1998.

(b) A. G. MacDiarmid, Synthetic Metals, A Novel Role for Organic Polymers, Angew. Chem. Int. Ed. 2001, 40, 2581.

(c) A. J. Heeger, Semiconducting and Metallic Polymers: The Fourth Generation of Polymeric Materials, A Novel Role for Organic Polymers, Angew. Chem. Int. Ed. 2001, 2591.

(d) J. Heinze, Electronically conducting polymers, Top. Curr. Chem. 1990, 152, 1.

(e) S. J. Higgins, Conjugated polymers incorporating pendant functional groups synthesis and characterisation, Chem. Soc. Rev. 1997, 26, 247. 
[2] J. H. Schon, C. Kloc, E. Bucher, B. Batlogg Nature 2000, 403, 408-410.

[3] K. Brunner, A. Van Dijken, H. Bôrner, J. J. A. M. Bastiaansen, B. M. W. Langeveld, J. Am.Chem.Soc. 2004, 126, 6035-6042.

[4] H. Nakanishi, Y. Aso, T. Otsubo Synth. Met .1999, 101, 604-605.

[5] T. Noda, H. Ogawa, N. Noma,Y. Shirota J. Mater. Chem. 1999, 9, 2177-2181.

[6] T. Otsubo, Y. Aso and K. Takimiya J. Mater. Chem. 2002, 12, 2565-2575.

[7] Z. Kotler, J. Segal, M. Sigalov, A. Ben-Asuly, V. Khodorkovsky Synth. Met. 2000, 115, $269-273$.

[8] P. Kundu, K. R. J. Thomas, J. T. Lin, Y.-T. Tao, C.-H. Chien Adv. Funct. Mater. 2003, 13, $445-452$.

[9] A. Van Dijken, J. J. A. M. Bastiaansen, N. M. M. Kiggen, B. M. W. Langeveld, C. Rothe, A. Monkman, I. Bach, P. Stossel, K. Brunner J. Am. Chem. Soc. 2004, 126, 7718-7727.

[10] B. C. Thompson, K. A. Abboud, J. R. Reynolds, K. Nakatani, P. Audebert New J. Chem. 2005, 29, 1128.

[11] (a) E. Hadjoudis, M. Mavridis Chem. Soc. Rev. 2004, 33, 579.

(b) E. Hadjoudis Photochromism: Molecules and Systems, ed H. Dürr, H. BouasLaurent, Elsevier, Amsterdam 1990, 685.

(c) K. Amimoto, T. Kawato J. Photochem. Photobiol. C: Reviews 2005, 6, 207.

[12] (a) S. Mitra, N. Tamai, Phys. Chem. Chem. Phys. 2003, 5, 4647.

(b) A. Ohshima, A. Momotake, T. J. Arai Photochem. Photobiol. A 2003, 162, 473.

[13] (a) M. Sliwa, S. Létard, I. Malfant, M. Nierlich, P. G. Lacroix, T. Asahi, H. Mashuhara, P. Yu, K. Nakatani Chem. Mater. 2005,17, 4727.

(b) T. Honeda, M. Kawano, T. Kojima, M. Fujita Angew. Int. Ed. 2007, 46, 46.

(c) K. Womiak, H. He, J. Klinowski, W.Jones, T. Dziembowska, E. Grech J. Chem. Soc., Faraday Trans. 1995, 77. 
(d) A. Mandal, A. Koll, A. Filarowski, D. Majumder, S. Mukherjee Spectrochim. Acta Part A 1999, 55, 2861 and references therein.

[14] (a) D. H. Heinert, A. E. Martell. J. Am. Chem. Soc. 1963, 85, 188.

(b) A. E. Martell, E. H. Abbott. J. Am. Chem. Soc. 1970, 92, 1764.

[15] P. Schottland, K. Zong, C. 1. Gaupp, B. C. Thompson, C. A. Thomas, I. Giurgiu, R. Hickman, K. A. Abboud, J. R. Reynolds Macromolecules 2000, 33, 7051-7061.

[16] Gaussian 03, Revision B.04, M. J. Frisch, G. W. Trucks, H. B. Schlegel, G. E. Scuseria, M. A. Robb, J. R. Cheeseman, J. A. Montgomery Jr., T. Vreven, K. N. Kudin, J. C. Burant, J. M. Millam,S. S. Iyengar, J. Tomasi, V. Barone, B. Mennucci, M. Cossi, G. Scalmani, N. Rega, G. A. Petersson, H. Nakatsuji, M. Hada, M. Ehara, K. Toyota, R. Fukuda, J. Hasegawa, M. Ishida, T. Nakajima, Y. Honda, O. Kitao, H. Nakai, M. Klene, X. Li, J. E. Knox, H. P. Hratchian, J. B. Cross, C. Adamo, J. Jaramillo, R. Gomperts, R. E. Stratmann, O. Yazyev, A. J. Austin, R. Cammi, C. Pomelli, J. W. Ochterski, P. Y. Ayala, K. Morokuma, G. A. Voth, P. Salvador, J. J. Dannenberg, V. G. Zakrzewski, S. Dapprich, A. D. Daniels, M. C. Strain, O. Farkas, D. K. Malick, A. D. Rabuck, K. Raghavachari, J. B. Foresman, J. V. Ortiz, Q. Cui, A. G. Baboul, S. Clifford, J. Cioslowski, B. B. Stefanov, G. Liu, A. Liashenko, P. Piskorz, I. Komaromi, R. L. Martin, D. J. Fox, T. Keith, M. A. Al-Laham, C. Y. Peng, A. Nanayakkara, M. Challacombe, P. M. W. Gill, B. Johnson, W. Chen, M. W. Wong, C. Gonzalez, J. A. Pople, Gaussian, Inc., Pittsburgh PA, 2003.

[17] A. D. Becke J. Chem. Phys. 1993, 98, 5648.

[18] P. C Hariharan, J. A. Pople Chem. Phys. Lett. 1972, 16, 217.

[19] K. Smith, D. M. James, A. G. Mistry, M. R. Bye, D. J. Faulkner Tetrahedron 1992, 48, 7479-7488.

[20] Z. Zhu, J. S. Moore Macromolecules 2000, 33, 801-807. 
[21] M. H. Davey, V. Y. Lee, L. -M. Wu, C. R. Moylan, W. Volksen, A. Knoesen, R. D. Miller, T. J. Marks Chem. Mater. 2000, 12, 1679-1693.

[22] J. H. Chong, M. Sauer, B. O. Patrick, M. J. MacLachlan Organic Letters 2003, 5, 38233826.

[23] J. Cajaj, K. Idzik, J. Soloducho, A. Chyla Tetrahedron 2006, 62, 758-764.

[24] C. Edder, J. M. J. Fréchet Organic Letters 2003, 5, 1879-1882.

[25] D. Deffieux, I. Fabre, A. Titz, J. -L. Léger, S. Quideau J. Org. Chem. 2004; 69, 87318738.

[26] (a) E. Stokeim (Ed.), Handbook of Conducting Polymers 1986, vol. 1, vol. 2.

(b) S. Sadki, C. Chevrot Electrochimica Acta 2003, 48, 733-739.

[27] (a) V. T. Kasumov, A. A. Medjidov, N. Yayli, Y. Zeren Spectrochimica Acta, PartA :

Molecular and Biomolecular Spectroscopy 2004, 60A, 3037-3047.

(b) V. T. Kasumov, F. Koeosal, R. Koeseoglu Journal of Coordination Chemistry 2004, 57, 591-603.

[28] (a) P. Audebert, P. Hapiot Synth. Met. 1995, 75, 95.

(b) P. Audebert, J. M. Catel, G. Le Coustumer, V. Duchenet, P. Hapiot J. Phys. Chem. B 1998, 102, 8661 .

[29] (a) J. L. Reddingner, G. A. Sotzing, J. R. Reynolds Chem. Commun. 1996, 1777.

(b) G. A. Sotzing, J. L. Reddinger, A. R. Katritzky, J. Soloducho, R. Musgrave, J. R.

Reynolds, P. J. Steel Chem. Mater. 1997, 9, 1578-1587.

(c) C. L. Gaupp, J. R. Reynolds Macromolecules 2003, 63, 6305-6315.

[30] V. Promarak, S. Ruchirawat Tetrahedron 2007, 63, 1602-1609.

[31] (a) S. Garreau, G. Louarn, J. P., Buisson, G. Froyer, S. Lefrant Macromolecules 1999, 32, 6807-6812. 
(b) W. L. Lao, C. Xu, S. Ji, J. Yiu, Q. Ou Spectrochemica acta part A 2000, 56, 20492060.

(c) W. Turek, E. Stochmal-Pomarzanska, A. Pron, J. Haber Journal of Catalysis 2000, 189, 297-313.

\section{Acknowledgment}

This research was supported by the CEA Chimtronique Program for Isabelle Fabre-Francke research assistantship. One of the authors (M.Z.) wants to acknowledge a partial financial support of the Warsaw University of Technology. 


\section{Captions}

Scheme 1. Synthetic route to the preparation of monomer EDOT-Cz-Anil 8.

Scheme 2. Dimer electrosynthesis

Fig.1 . Cyclic voltammogramms of:

a) Monomer EDOT-Cz-Anil 8 at a concentration of $3.8 \mathrm{mM}$ in acetonitrile containing $\mathrm{NBu}_{4} \mathrm{ClO}_{4}(0.1 \mathrm{M})$; platinum working electrode; potential versus $\mathrm{Fc} / \mathrm{Fc}^{+} ; \mathrm{v}=50 \mathrm{mV} . \mathrm{s}^{-1}$.

b) Compound 9 at a concentration of $1.4 \mathrm{mM}$ in acetonitrile containing $\mathrm{NBu}_{4} \mathrm{ClO}_{4}(0.1 \mathrm{M})$; platinum working electrode; potential versus $\mathrm{Fc} / \mathrm{Fc}^{+} ; \mathrm{v}=200 \mathrm{mV} . \mathrm{s}^{-1}$.

Fig.2. Electrodimerization of monomer EDOT-Cz-Anil 8 by cyclic voltamperometry at a concentration of $3.8 \mathrm{mM}$ in acetonitrile containing $\mathrm{NBu}_{4} \mathrm{ClO}_{4}(0.1 \mathrm{M})$ at a platinum working electrode; potential versus $\mathrm{Fc} / \mathrm{Fc}^{+} ; \mathrm{v}=50 \mathrm{mV} . \mathrm{s}^{-1}$.

Fig .3. Spin densities (isosurfaces for 0.074 u.a.) calculated on the optimized geometry at the B3LYP/6-31G* level.

Fig.4. UV-vis-NIR spectrum of dimer 10 registered at the open circuit potential $(\mathrm{E}=-0.04 \mathrm{~V})$; ITO electrode; electrolyte $\mathrm{NBu}_{4} \mathrm{ClO}_{4}$ in acetonitrile $(0.1 \mathrm{M})$; potential versus $\mathrm{Fc} / \mathrm{Fc}^{+}$.

Fig.5.

a) Cyclic voltammogramm of dimer 10 in acetonitrile containing $\mathrm{NBu}_{4} \mathrm{ClO}_{4}(0.1 \mathrm{M})$; platinum working electrode; potential versus $\mathrm{Fc} / \mathrm{Fc}^{+} ; \mathrm{v}=20$ (a)-100 (f) $\mathrm{mV} . \mathrm{s}^{-1}$. 
b) Peak current as a function of scan rate for the second electronic transfer in acetonitrile containing $\mathrm{NBu}_{4} \mathrm{ClO}_{4}(0.1 \mathrm{M})$; platinum working electrode; potential versus $\mathrm{Fc} / \mathrm{Fc}^{+}$.

Fig.6. Optimized geometry of the dimer 10 calculated at the B3LYP/6-31G* level.

Fig.7. UV-vis-NIR spectra of dimer $\mathbf{1 0}$ registered for increasing electrode potentials; ITO working electrode; electrolyte $\mathrm{NBu}_{4} \mathrm{ClO}_{4}$ in acetonitrile $(0.1 \mathrm{M})$; potential versus $\mathrm{Fc} / \mathrm{Fc}^{+}$.

Fig.8. Raman spectra of dimer $\mathbf{1 0}$ registered for increasing electrode potentials; ITO working electrode; electrolyte $\mathrm{NBu}_{4} \mathrm{ClO}_{4}$ in acetonitrile $(0.1 \mathrm{M})$; potential versus $\mathrm{Fc} / \mathrm{Fc}^{+} ; \lambda_{\text {exc }}=1064$ $\mathrm{nm}$. 


\section{Schemes and Figures}
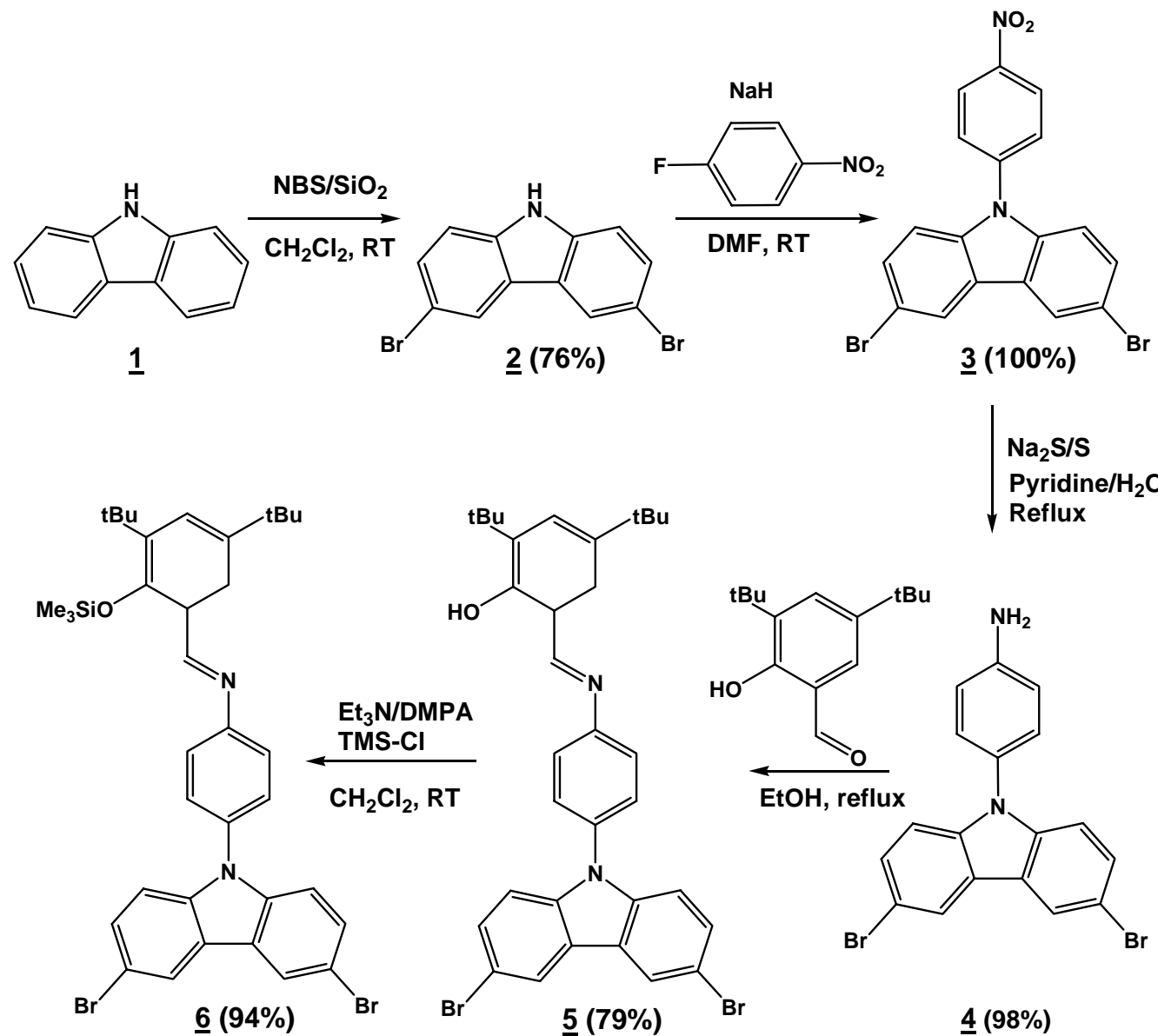

$\mathrm{Na}_{2} \mathrm{~S} / \mathrm{S}$

Pyridine $/ \mathrm{H}_{2} \mathrm{O}$

Reflux

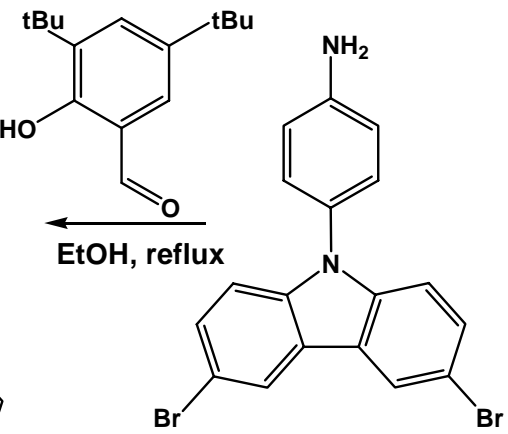

$\underline{4}(98 \%)$<smiles>COC1=C(C(C)C)C=C(CC(C)C)CC1C=Nc1ccc(-n2c3ccc(Br)cc3c3cc(Br)ccc32)cc1</smiles>

$\underline{6}$<smiles>CC(C)(C)C1=CC(C(C)(C)C)=C(O)C(/C=N/c2ccc(-n3c4ccc(Br)cc4c4cc(-c5scc6c5OCCO6)ccc43)cc2)C1</smiles> 
Scheme 1. Fabre-Francke et al.
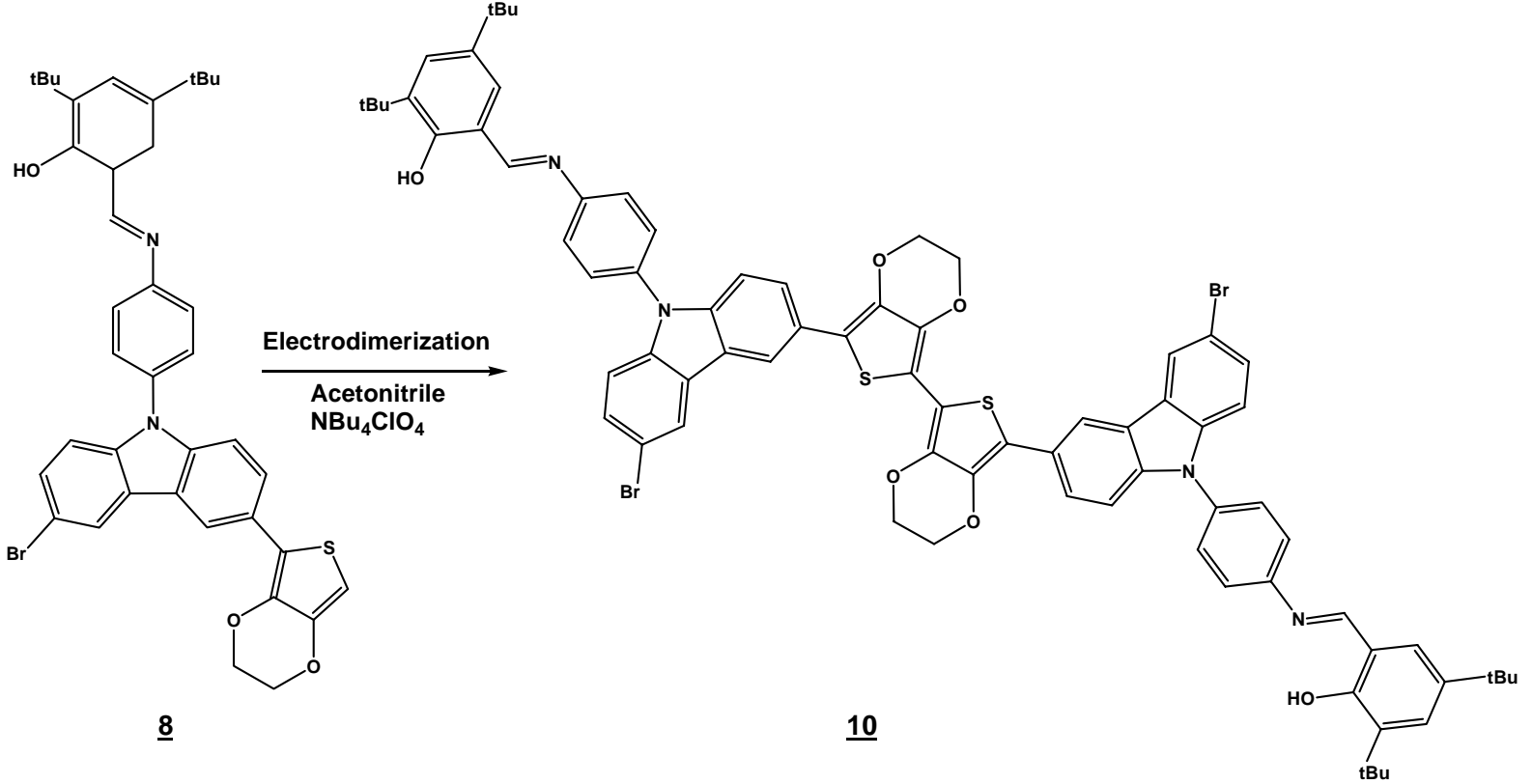

Scheme 2. Fabre-Francke et al. 

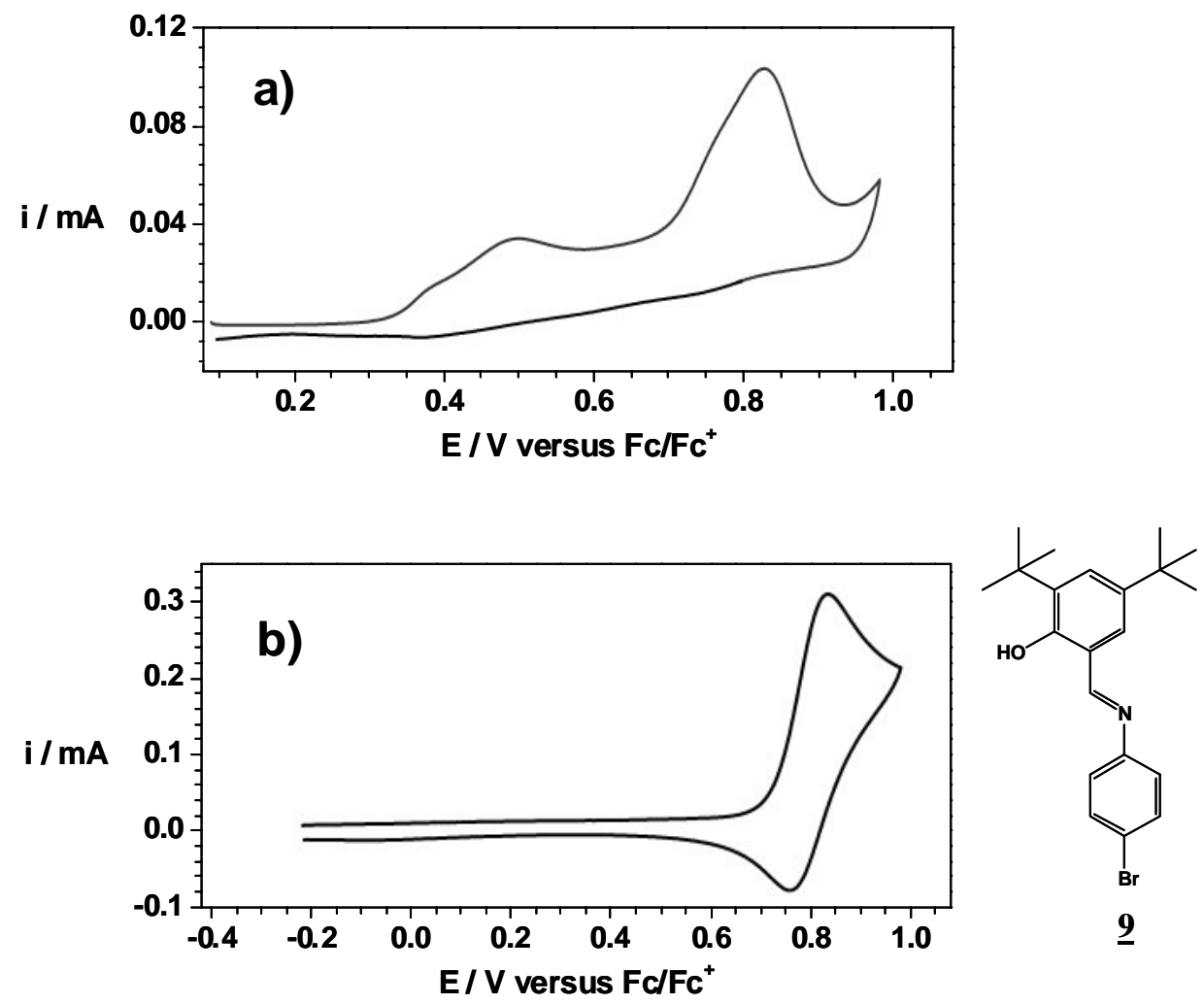

Fig.1. Fabre-Francke et al. 


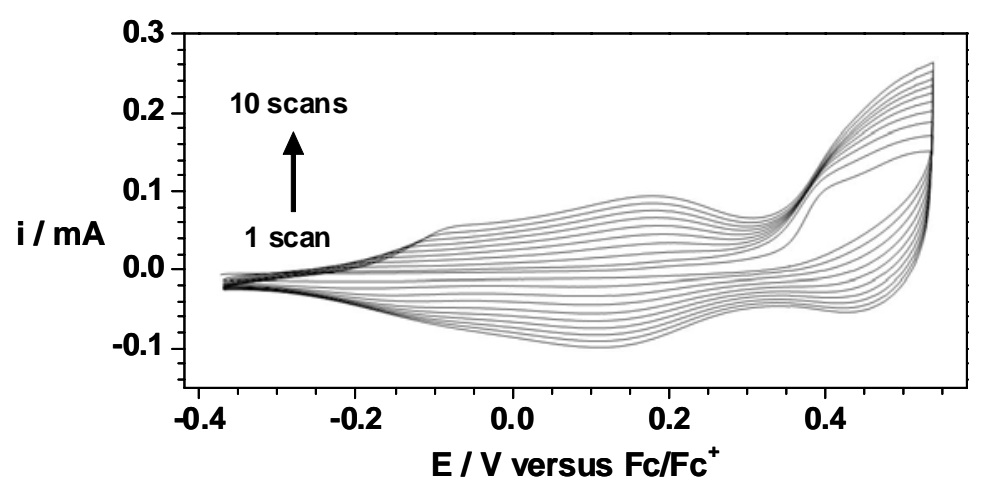

Fig.2. Fabre-Francke et al.

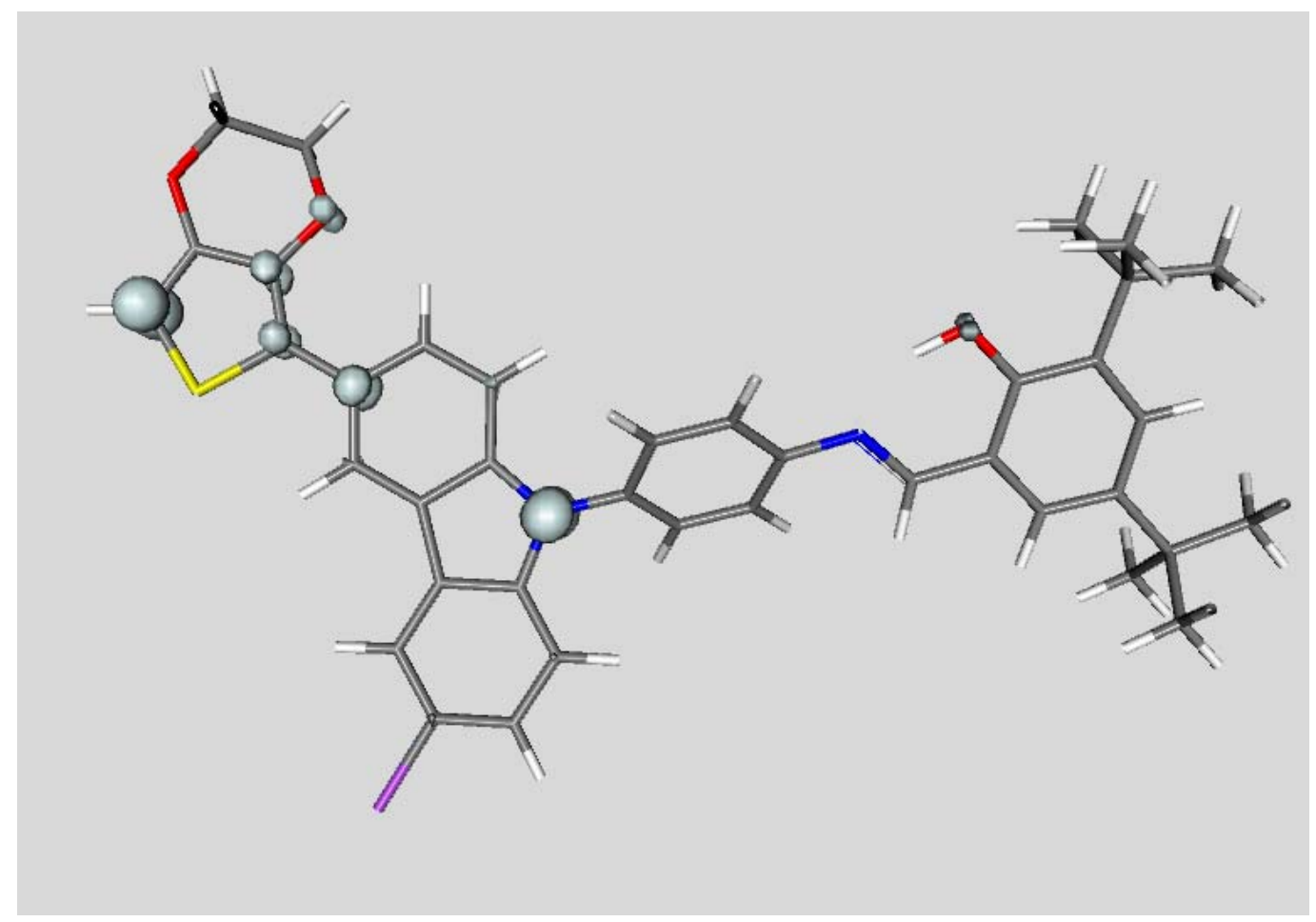

Fig.3. Fabre-Francke et al. 


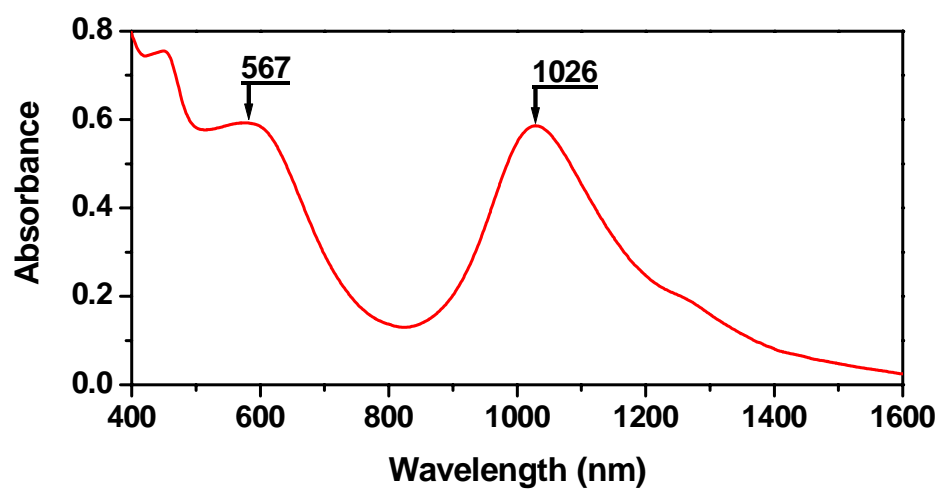

Fig.4. Fabre-Francke et al.
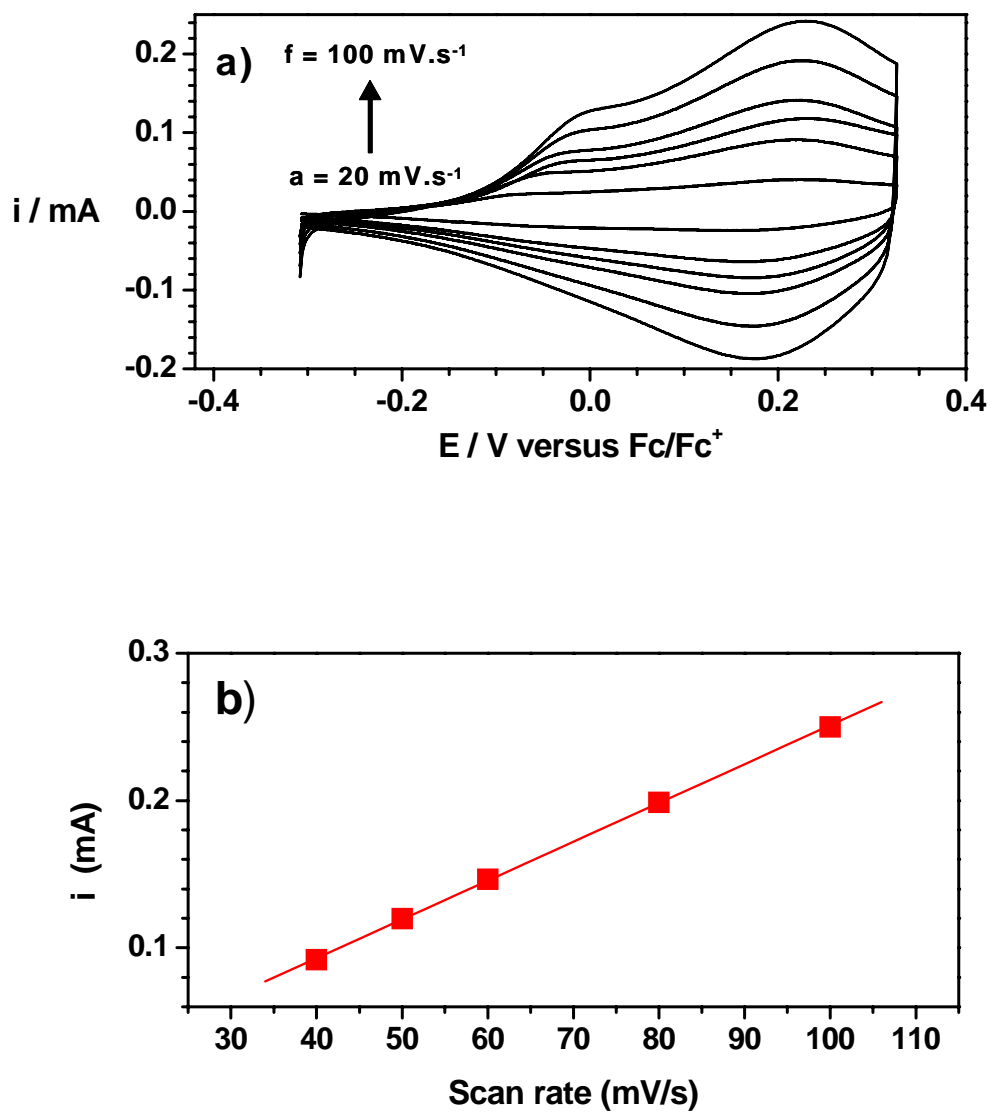

Fig.5. Fabre-Francke et al. 


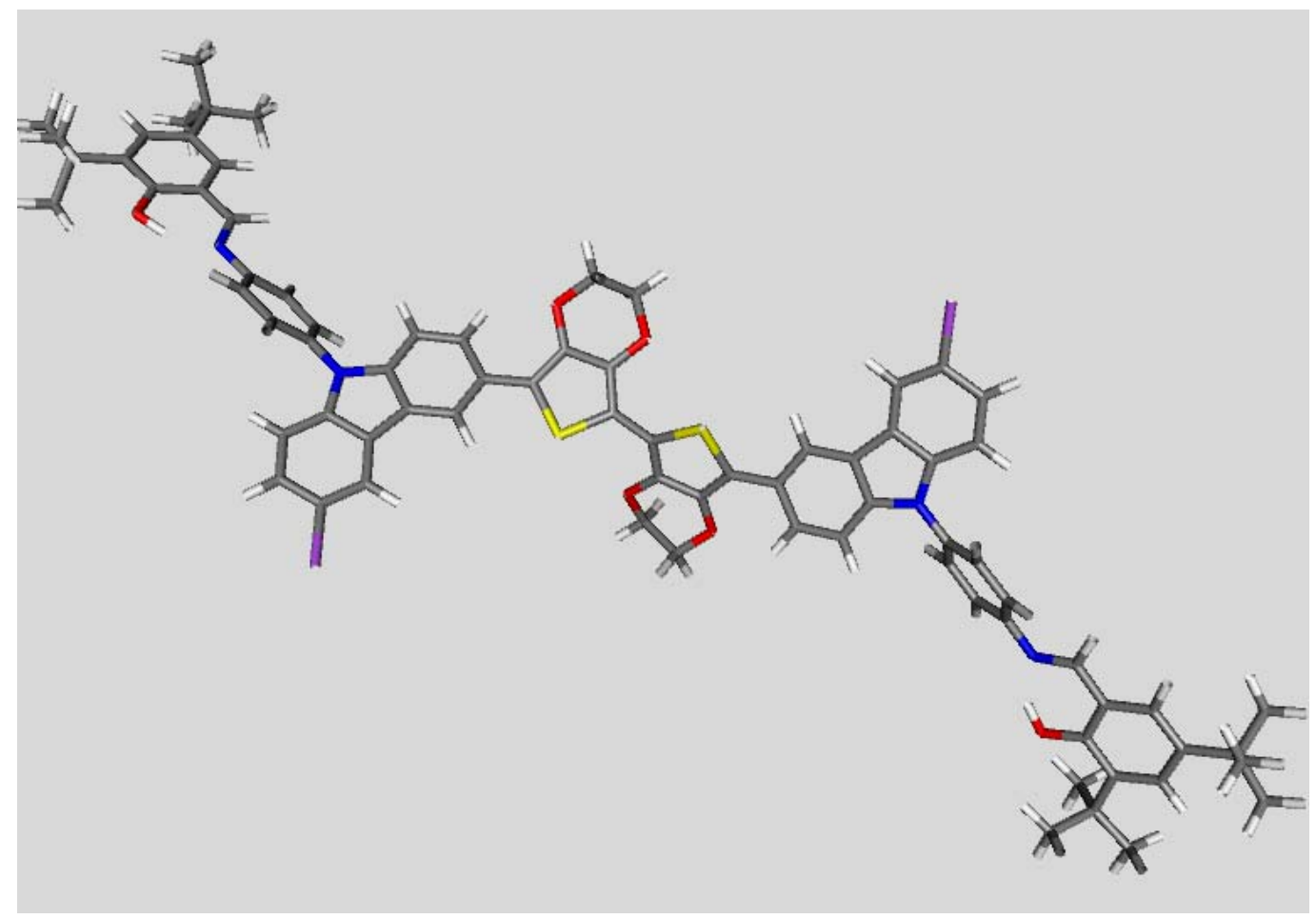

Fig.6. Fabre-Francke et al.

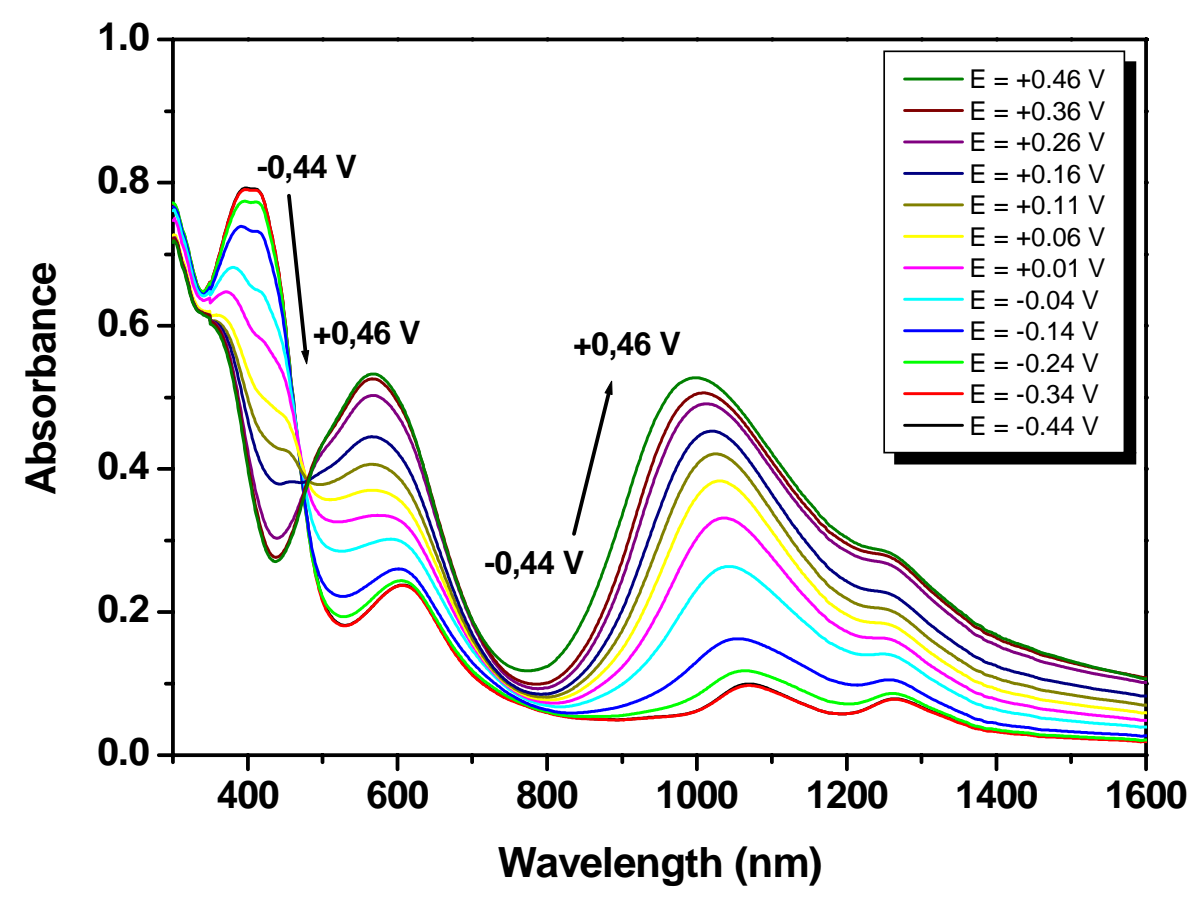

Fig.7. Fabre-Francke et al. 


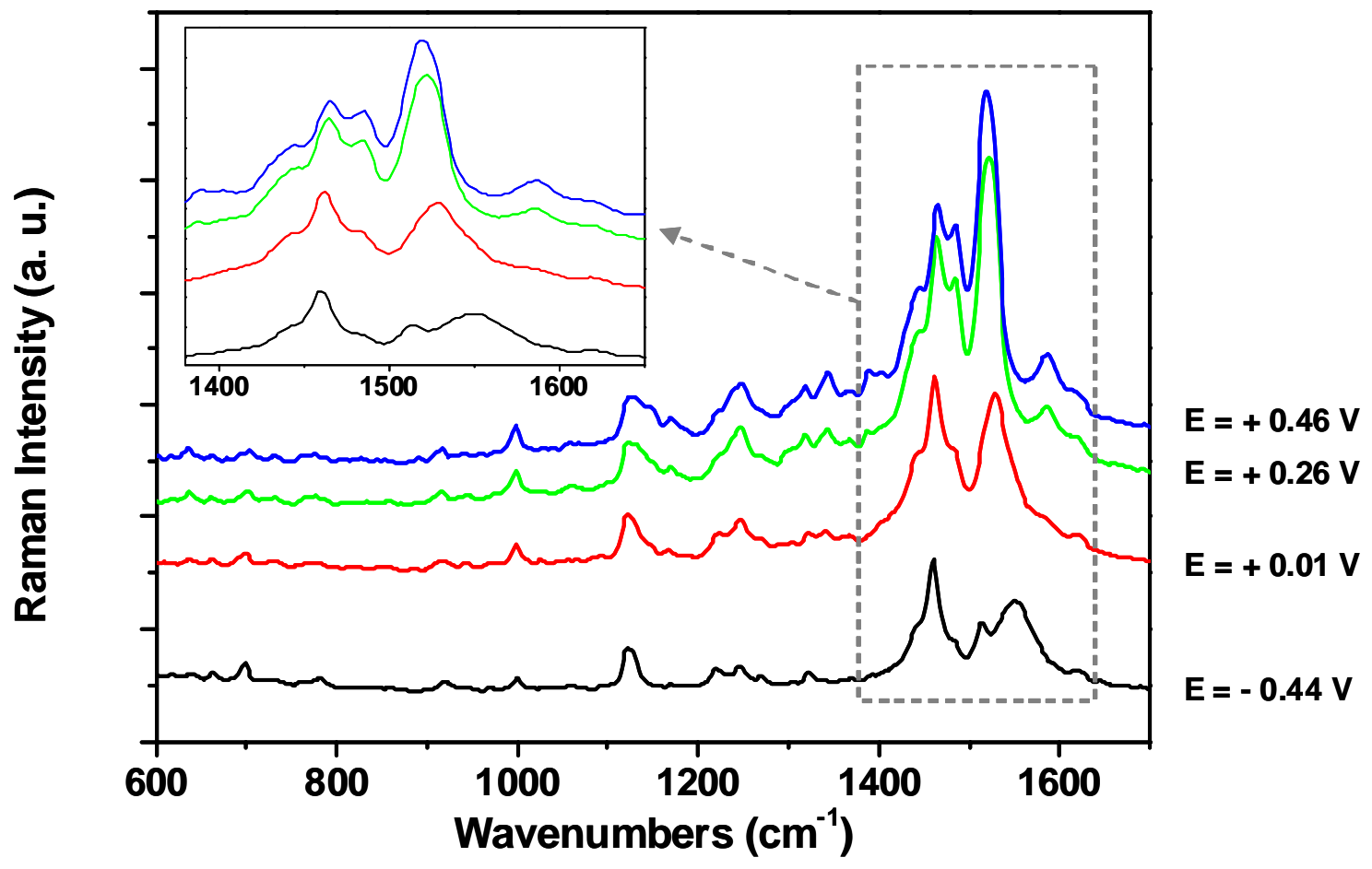

Fig.8. Fabre-Francke et al. 